\title{
Control Design of a Neutral Point Clamped Converter Based Active Power Filter for the Selective Harmonic Compensation
}

\author{
José Luis Monroy Morales, Máximo Hernández Ángeles \\ Programa de Graduados e Investigación en Ingeniería Eléctrica \\ Instituto Tecnológico de Morelia \\ Morelia, Michoacán México \\ Email: jlmonroy_m@itmorelia.edu.mx, \\ mhernand_it@yahoo.com.mx
}

\author{
David Campos-Gaona, Rafael Peña-Alzola \\ Department of Electrical and Computer Engineering \\ The University of British Columbia \\ 2332 Main Mall. Vancouver, BC Canada V6T 1Z41 \\ Email: davidcg@ieee.org,rafapeal@gmail.com
}

\begin{abstract}
This paper presents the control of an active power filter (APF) based on a 3-phase, 3-level neutral point clamped (NPC) converter with selective harmonic compensation. To achieve the selective harmonic compensation, the APF use several synchronous rotatory frames, which are rotating at the angular frequency and sequence of their respective harmonics, to detect and control the magnitude and angle of each individual harmonic using $d$ and $q$ variables. A three dimensional space vector modulator (3D-SVPWM) is used to generate the compensation currents. Due to its multilevel topology, the proposed active power filter can be used in high voltage power quality applications, such as sub-transmission and distribution levels. Simulation results are shown to validate the proposed solution and corroborate the proper function of the multilevel active power filter.
\end{abstract}

Keywords: Active Power Filters, Neutral Point Clamped, Selective Harmonic Compensation, Overall Harmonic Compensation.

\section{INTRODUCTION}

Energy quality issues are an important aspect in the electrical energy consumption. That way, the harmonics in power systems results in several problems due to the wide application of power electronic equipment and nonlinear loads. Harmonic distortion causes several problems such as increased power losses, excessive heating in rotating machinery, electromagnetic interference in communication systems and operation failures of protection devices and electronic equipments [1]. Additionally, non-sinusoidal currents produce low power factor and high total harmonic distortion. Because of this, the modernization on transmission and distribution grids require new systems based on power electronic converters, with favorable characteristics such as, high efficiency, high power density, and low harmonic distortion, to suitable into the distributed generation and smart-grids concepts. A multilevel NPC converter topology can be used at higher power applications as APF. Thus, it can be applied in transmission, sub transmission, wind, photo-voltaic and mining system.
The APF performance depends on its controller which is divided in two parts. The first part determines the fundamental and harmonic reference current of the APF and maintains a stable $D C$ bus voltage. Due to, several harmonic current detection methods, such as instantaneous reactive power theory, synchronous reference frame method, and supplying current regulation can be used [2-5]. These methods measure the harmonic currents either from the load or from the mains current to generate a reference harmonic current that will cancel out the grid currents at the point of common coupling. The second part is related to generate the compensating current into the $A C$ mains. Therefore, several modulation techniques are implemented for driving the inverter. Among these methods, the pulse width modulation (PWM) techniques have been employed in APFs for harmonics elimination [6]. With the development of high speed microprocessors, space vector modulation (SVM) has become one of the most important PWM methods for three phase converters. The SVM based PWM methods have several advantages over carrier based ones such as lower total harmonic distortion (THD) and higher efficiency and higher available $D C$-link $[7,8]$.

The 3D-SVPWM is an useful algorithm used in multilevel level converters. This modulation technique optimizes the number of commutations and the number of calculations to get the switching sequence and the duty cycles [9-11].

This paper presents the control of an active power filter (APF) based on a 3-phase, 3-level neutral point clamped (NPC) converter with selective harmonic compensation. Figure 1 shows the APF with three level converter topology. To achieve the selective harmonic compensation, the APF use several synchronous rotatory frames, which are rotating at the angular frequency and sequence of their respective harmonics, to detect and control the magnitude and angle of each individual harmonic using $d$ and $q$ variables. A 3D-SVPWM is used to generate the compensation currents. The multi level 
topology has the advantages to be used in high voltage power quality applications, such as sub-transmission and distribution levels. Simulation results are shown to validate the proposed solution and corroborate the proper function of the multilevel active power filter.

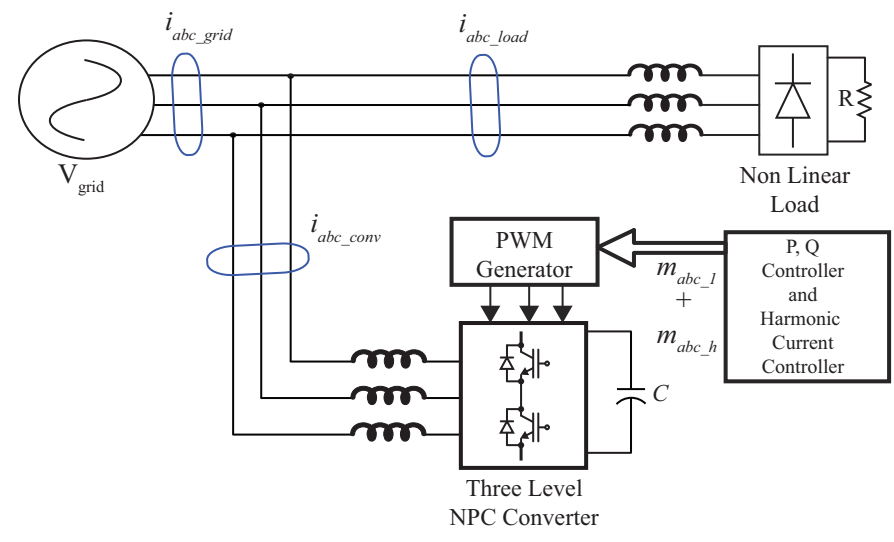

Fig. 1. Active power filter with three level inverter topology.

\section{THREE LEVEl CONVERTER}

In a multilevel NPC converter topology, the voltages stress across the switches are lower and there are more available control vectors. Thus, the harmonic content of the converter is reduced if appropriate switching vectors are selected [12].

A three-phase three-level NPC converter is shown in Figure 2. The three phases have a common $D C$ bus, divided by two capacitors into three levels. The voltage across each capacitor is $V_{D C} / 2$; and the voltage stress across each switching device is limited to $V_{D C} / 2$ through the clamping diodes. A threelevel NPC converter is able to produce five levels of line to line voltage and three levels of phase voltage. This NPC converter reduces harmonics in both voltage and current output.

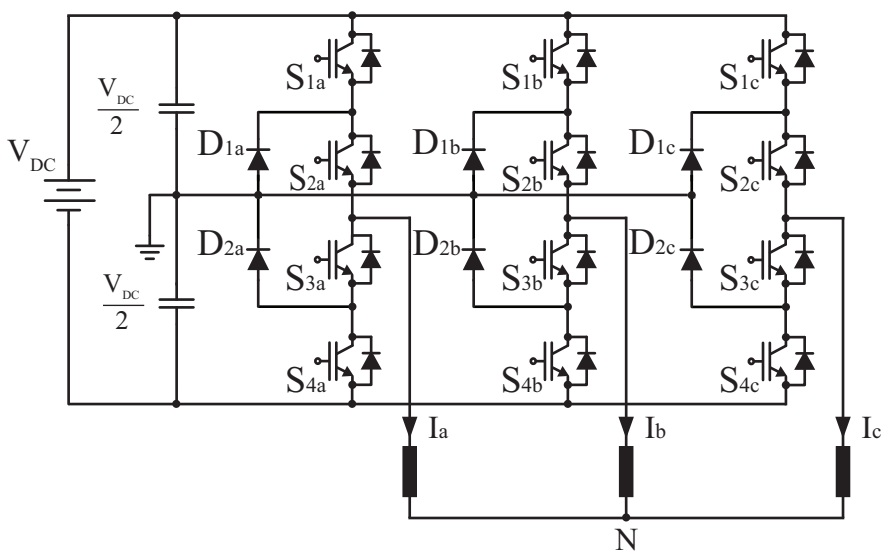

Fig. 2. Three-level NPC inverter topology.

Table I gives the switch states for phase $a$. Similar switching sequence will be derived for other phases by according the phase angle displacement. Here, $S_{1 a}$ and $S_{3 a}$ are complement of each other and $S_{2 a}$ and $S_{4 a}$ are complement of each other.

TABLE I

SWITCHING STATES OF THREE-LEVEL NPC CONVERTER

\begin{tabular}{|c|c|c|c|c|}
\hline \multicolumn{4}{|c|}{ States of switches } & Voltage \\
\hline$S_{1 a}$ & $S_{2 a}$ & $S_{3 a}$ & $S_{4 a}$ & $\begin{array}{l}\text { Level } \\
V_{a N}\end{array}$ \\
\hline 1 & 1 & 0 & 0 & $+\mathrm{Vdc} / 2$ \\
\hline 0 & 1 & 1 & 0 & 0 \\
\hline 0 & 0 & 1 & 1 & $-\mathrm{Vdc} / 2$ \\
\hline
\end{tabular}

State condition 1 means switch $\mathrm{ON}$ and 0 means switch OFF. Now, it is clear that an $m$-level diode clamped converter consists of $(m-1)$ capacitors on $d c$ bus, output phase voltage has $m$-levels and output line voltage has $(2 m-1)$-levels. Each active switching device has to withstand a blocking voltage of $\mathrm{Vdc} /(m-1)$, even then clamping diode must have different voltage ratings for reverse voltage blocking. The number of diodes required will be $2(m-2)$ and the number of switching required will be $2(m-1)$ for each phase. Where $m$ is the number of levels of the converter [8].

\section{HARMONIC DETECTION DQ USING SYNCHRONOUS REFERENCE FRAME}

In the synchronous reference frame (SRF) algorithm, synchronous harmonic $d-q$ frame rotates at a frequency and sequence equal to the selected harmonic. Thus, in the harmonic $d-q$ frame, only the respective harmonic will be a $d c$-signal and all other frequencies including the fundamental will be $a c$-components. The detection of the respective harmonic results in removing the $a c$-signals with low pass filters (LPF). As seen in Fig. 3, the load current $i_{a b c_{-} \text {load }}$ is measured and fed to the multiple synchronous reference frames. Each frame provides the $d-q$ components of each harmonic plus an $a c$ signal. The $a c$ signal of the harmonic $d-q$ components is filtered by a low pass filter based on the moving average architecture. The current of the inverter $i_{a b c_{-} i n v}$ is also fed to the multiple synchronous frames and the resulting $d-q$ signals are also filtered by a low pass filter with the same characteristics and delay as the $d-q$ load harmonic currents. The filtered $d-q$ harmonic currents from the load and the inverter are then fed to a PI controller. The PI controller generates, as a control action, a modulator signal that would produce harmonic currents of magnitudes that match those of the load, but in opposite polarity. In consequence, the load harmonic currents would cancel out with the inverter harmonic currents at the point of common coupling $[5,13]$.

In addition, a limiter is added after every PI regulator in order to ensure that the harmonic currents never increase beyond their allowed range. Otherwise, inverter voltage references may become greater than the maximum voltage allowed by the $D C$ capacitor. This produce saturation in the modulator 
signal which in turn produces unwanted harmonic content. The main advantage of a selective harmonic compensation (SHC) mode over an overall harmonic compensation (OHC) mode is the ability to select individual harmonics to compensate. Therefore, SHC systems can be installed in parallel to cancel individual harmonics from separate units.

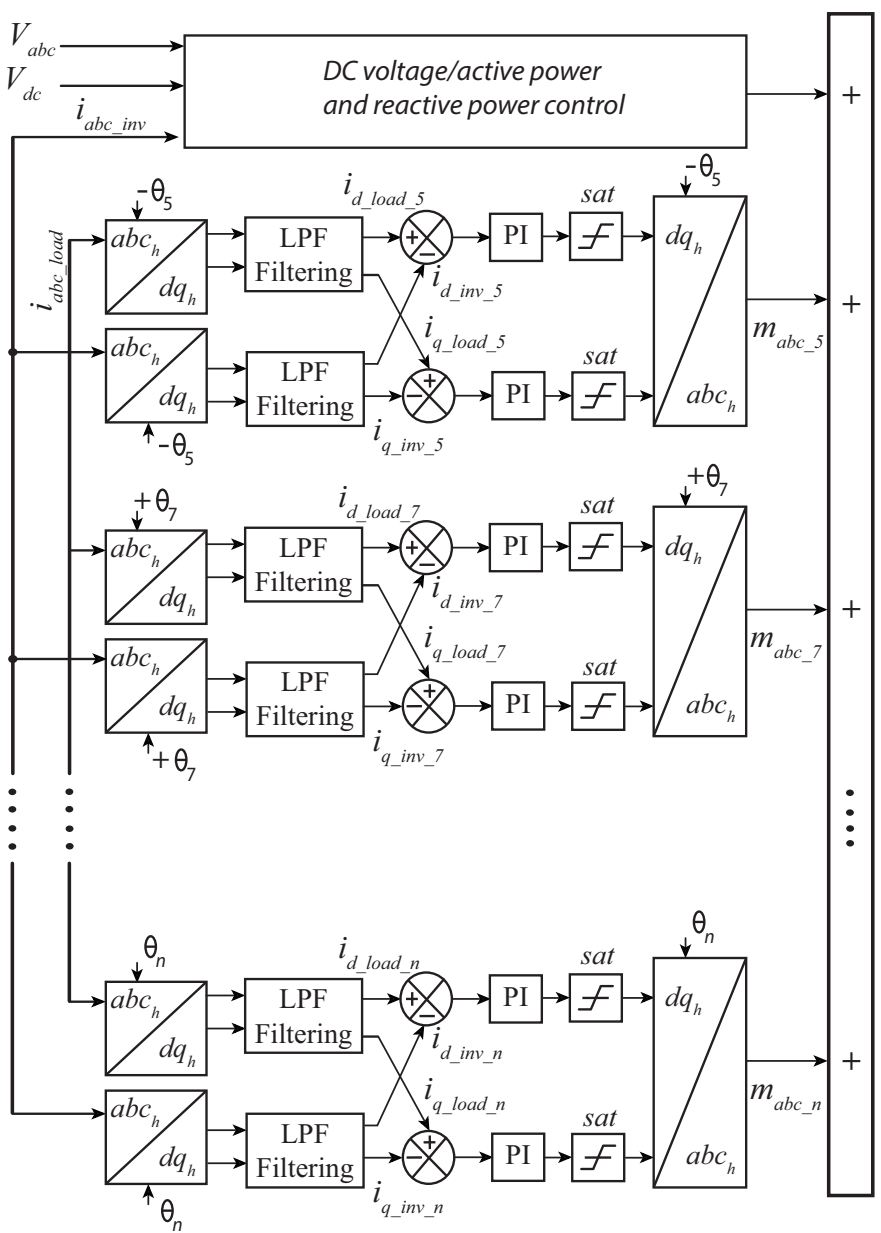

Fig. 3. Selective harmonic compensation based synchronous reference frame.

\section{Active Power Filter Controller}

The overall APF selective harmonic controller is shown in Figure 4. A vectorial control is carried out to achieve the selective APF controller, three phase currents and voltages are described as vectors in a complex reference frame, called $\alpha-\beta$ frame. A rotating reference frame synchronized with the $a c$ grid is also introduced. As the $d-q$ frame, is synchronized to the grid, the voltages and currents occur as constant vectors in the $d-q$ reference frame in steady state. The value of the angle $\theta$ is calculated by using a synchronization technique phase locked loop (PLL). The PLL information is used to synchronize the turning on/off of the power devices, calculate and control the active/reactive power flow by transforming the feedback variables to a reference frame suitable for control purposes [14].

As the vector control technique offers decoupled control of

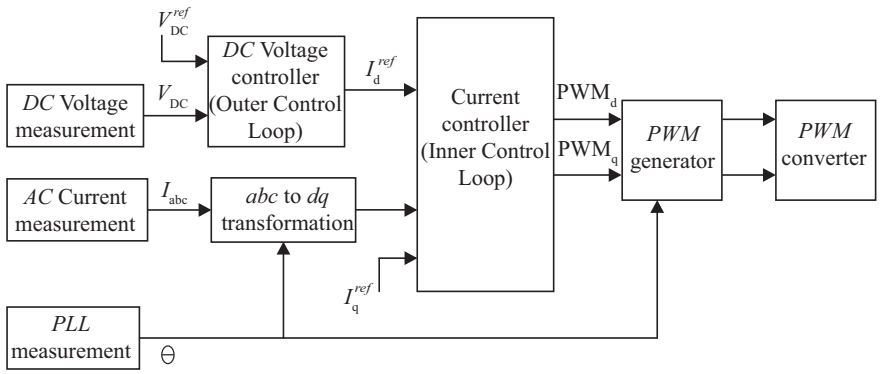

Fig. 4. Overall Scheme of Vectorial Control

active and reactive power and a fast dynamics, it makes the realization of system control in form of cascade structure possible, with two PI control loops in cascade. Meaning this, an outer control loop and inner current control. The control system is based on a fast inner current control loop controlling the $a c$ current. The $a c$ current references are supplied by outer controllers. The inner and outer controller are described below.

\section{A. Inner and Outer Controller}

The inner current control loop can be implemented in the $d-q$ frame, based on the basic relationship of the system model. A general inner current control block is represented in Figure 5.

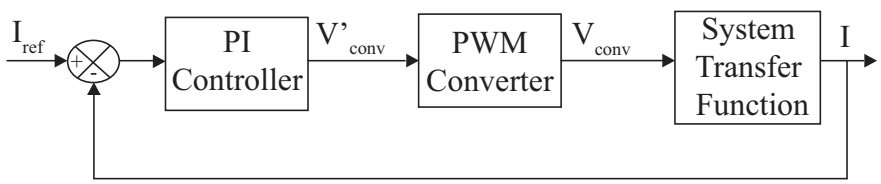

Fig. 5. General block diagram of inner current control.

Inside the current control block, there are two PI regulators, respectively for $d$ and $q$ axis current control. They transform the error between the comparison of $d$ and $q$ components of current into voltage value. In order to have a detail overview of the control system, each block of the control system is discussed as below.

The representative equation of the $P I$ regulator is:

$$
R(s)=K_{p}+\frac{K_{i}}{s}=K_{p} \cdot\left(\frac{1+T_{i} . s}{T_{i} . s}\right)
$$

considering the $I(s)$ and $I_{r e f}(s)$ and $P I$ controller block,

$$
\left\{I_{\text {ref }}(s)-I(s)\right\}\left(K_{p}+\frac{K_{i}}{s}\right)=V_{\text {conv }}^{\prime}(s) .
$$

The PWM converter block is considered as an ideal power transformer with a time delay. Thus the PWM block is given as,

$$
V_{\text {conv }}^{\prime}(s) \cdot \frac{1}{1+T_{a} \cdot s}=V_{\text {conv }}(s)
$$

where $T_{a}=T_{\text {switch }} / 2$. 
Considering the converter system connected to grid, as seen in Figure 1, the phase voltages and currents are given by the equation,

$$
V_{a b c}=R . i_{a b c}+L \frac{d i_{a b c}}{d t}+V_{a b c, c o n v}
$$

where $V_{a b c}$ and $i_{a b c}$, are $a c$ voltages and currents respectively, and $v_{a b c, c o n v}$ is the voltage converter. $R$ and $L$ are the resistance and filter inductance between the converter and the $a c$ system. Using the $a b c$ to $d-q$ transformations, the 3-phase currents and voltages converter are expressed in 2-axis $d-q$ reference frame, synchronously rotating at given $a c$ frequency $w$ as

$$
\begin{aligned}
& V_{d}=R . i_{d}+L \frac{d i_{d}}{d t}-\omega L i_{q}+V_{d c o n v} \\
& V_{q}=R . i_{q}+L \frac{d i_{q}}{d t}+\omega L i_{d}+V_{q c o n v}
\end{aligned}
$$

Similarly on the output side,

$$
I_{d c}=C \cdot \frac{d V_{d c}}{d t}+I_{L}
$$

As seen from equations (5) and (6) the equations in $d$ and $q$ axis have a similar form, for this reason only the $d$ axis equations is used for further analysis and control rule derivation. The inner loop current controllers for $i_{d}$, gives the output of $V_{d}$ voltage reference signals, which fed to the converter. Using Equation (5),

$$
V_{\text {dconv }}=\left(i_{\text {dref }}-i_{d}\right) \cdot\left(K_{p}+\frac{K_{i}}{s}\right) \cdot \frac{1}{1+s T_{a}}
$$

The transformed $d-q$ voltage equations have the frequency induced terms, $w L i_{d}$ and $w L i_{q}$, that produces a cross coupling between the $d$ and $q$ currents. This cross coupling term can be cancelled out algebraically in the control loops, enabling an independent control in $d$ and $q$ axis, respectively. With the compensation terms used for decoupling, the system input from converter is defined as

$$
V_{d c o n v}^{\prime}=-\left(i_{d r e f}-i_{d}\right) \cdot\left(K_{p}+\frac{K_{i}}{s}\right)+w L i_{q}+V_{d}
$$

Equation (9) when substituted in Eqn. (3) and equated to equation (5), it gives,

$$
L \frac{d i_{d}}{d t}+R i_{d}=V_{d c o n v}
$$

by Laplace transformation the equation becomes:

$$
s \cdot I_{d}(s)=-\frac{R}{L} \cdot I_{d}(s)+\frac{1}{L} \cdot V_{d c o n v}(s) .
$$

Thus,

$$
I_{d}(s)=\frac{1}{s \cdot L+R} \cdot V_{d c o n v}(s)
$$

Hence the system transfer function is:

$$
G(s)=\frac{1}{R} \cdot \frac{1}{1+s \cdot \tau}
$$

Where the time constant is defined as $\tau=L / R$.

Since the control of the inverter fundamental currents and harmonic is carried out by $d c$ signals, the modulus optimum tuning criteria can be used to select the constants of the $P I$ controllers. If considering the cross coupling terms the $d-q$ current equations and the grid voltage components are disturbances, not present during the calculation of the $d-q$ current control, but instead being numerically compensated by a feed-forward loop in the main harmonic current control loop, then, the plant for $d-q$ fundamental and harmonic currents is:

$$
G(s)=\frac{i_{d \_h}(s)}{V_{d c o n v_{\_} h}(s)}=\frac{i_{q_{h} h}(s)}{V_{q c o n v_{-} h}(s)}=\frac{i_{h}(s)}{V_{\text {conv }_{h}}(s)}
$$

where $V_{d c o n v_{-} h}$ and $V_{q c o n v_{-} h}$ are the $d-q$ components of the average voltages generated by the inverter for the harmonic $h, i_{d_{-} h}$ and $i_{q_{-}} h$ are the $d-q$ components of the current between the inverter and the grid for the harmonic $h$.

From (13) it can be seen that the system has a stable pole at $-R / L$. This pole can be cancelled with the zero provided by the $P I$ controller, where $K p_{\text {conv } h} h$ and $K i_{\text {conv_ } h}$ are the proportional and integral constants of the $h$ harmonic $P I$ current controller. Thus, choosing $K i_{\text {conv } \_h} / K p_{\text {conv } \_h}=R / L$ and $K p_{\text {conv } \_h} / L=1 / \tau_{\text {conv } \_h}$, where $\tau_{c o n v_{-} h}$ is the time constant of the closed-loop system.

The power balance in the system is achieved through the $d c$ voltage controller. The general diagram for the outer controller is shown in Figure 6. The diagram consists of a $P I$ controller, the inner controller and the power transfer function of the capacitor.

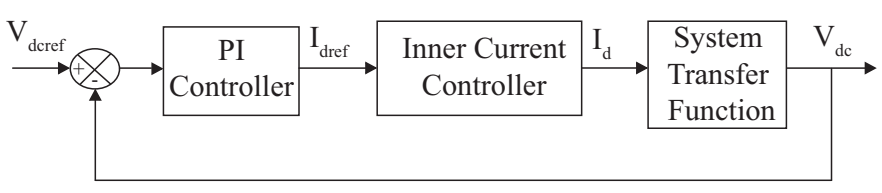

Fig. 6. General block diagram of outer $d c$ voltage control.

The representative equation of the $P I$ voltage regulator is:

$$
R(s)=K_{p v}+\frac{K_{i v}}{s}=K_{p v} \cdot\left(\frac{1+T_{i v} . s}{T_{i v} \cdot s}\right)
$$

where the subscript $v$ denotes the voltage regulator. For the PI controller block for outer voltage control,

$$
\left\{V_{d c r e f}(s)-V_{d c}(s)\right\}\left(K_{p v}+\frac{K_{i v}}{s}\right)=i_{d r e f}(s)
$$


The power balance relationship between the $a c$ input and $d c$ output is given as,

$$
P=\frac{3}{2}\left(V_{d} \cdot i_{d}+V_{q} \cdot i_{q}\right)=V_{d c} \cdot I_{d c}
$$

where $V_{d c}$ and $I_{d c}$ are $d c$ output voltage and current respectively. Using the condition $V_{q}=0$, the relation between $i_{d}$ and $I_{d c}$ can be written as,

$$
I_{d c}=\frac{3}{2} \cdot \frac{V_{d}}{V_{d c}} \cdot i_{d}
$$

This defines the value of the current gain to be used from $d c$ current to input current or viceversa. Substituting this value in (7), we get,

$$
C \frac{d V_{d c}}{d t}=\frac{3}{2} \cdot \frac{V_{d}}{V_{d c}} \cdot i_{d}-I_{L}
$$

It is possible to observe that the $d c$ link current equation is a nonlinear equation. For analyzing the stability of a nonlinear system in the neighbourhood of a steady state operating point, it is necessary to linearize the system model around the operating point and perform linear stability analysis. The reference point for linearization is found by specifying reference input, $V_{d c, \text { ref }}$ for the nonlinear model.Consequently the linear expression becomes,

$$
C \frac{d \Delta V_{d c}}{d t}=\frac{3}{2} \cdot \frac{V_{d, 0}}{V_{d c, r e f}} \cdot \Delta i_{d}
$$

By Laplace transformation it is:

$$
\frac{\Delta V_{d c}(s)}{\Delta i_{d}(s)}=\frac{3}{2} \cdot \frac{V_{d, 0}}{V_{d c, \text { ref }}} \cdot \frac{1}{s . C}
$$

The $d c$ link voltage controller controls the capacitor current so as to maintain the power balance. Hence under balanced conditions, $I c=0$. That is, $I_{d c}=I_{L}$. Thus, the reference value of $i_{d}$ should be,

$$
i_{d}=\frac{2}{3} \cdot \frac{V_{d c}}{V_{d}} \cdot I_{d c}
$$

The overall control block diagram of the $d c$ voltage controller based on equations (16)-(22) is as shown in Fig. 7. The inner

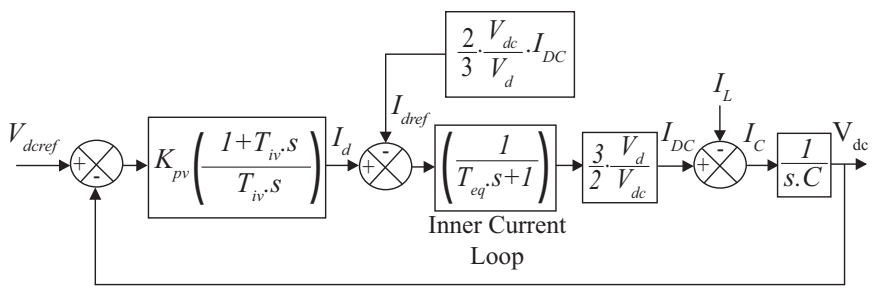

Fig. 7. Closed loop control diagram of dc voltage controller

control time response is selected in $1 \mathrm{~ms}$, hence, the outer control is selected 10 times this value in order to get a good performance of the controller.

\section{B. 3D-Space Vector Modulator}

The 3D-SVPWM algorithm optimizes the commutation sequence using four state vectors, which are adjacent to the reference vector, and determine the respective commutation times of the three-level converter switching devices. The reference vector is represented by means of four vertices of a tetrahedron which are the state vectors of the sequence switching. Figure 8 shows a tetrahedron in a sub-cube with corresponding state vectors.

The computational load is independent of the number of levels of the converter. In addition, the algorithm provides the switching sequence that minimizes the total harmonic distortion $(T H D)$ and the number of switchings of the semiconductor devices.

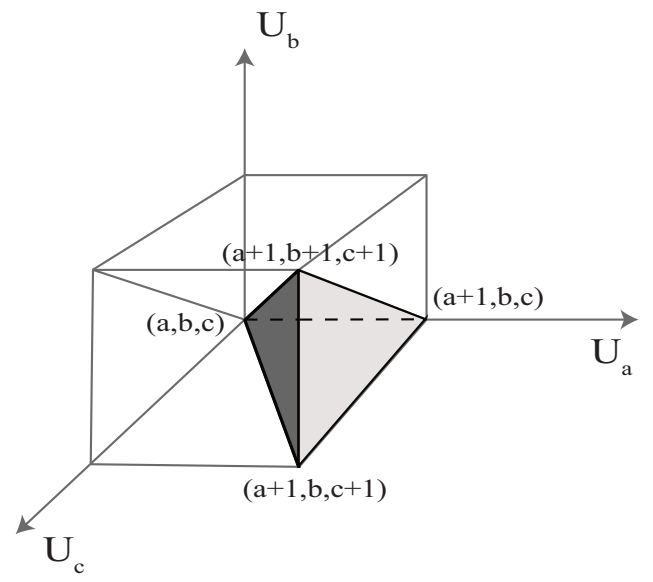

Fig. 8. Tetrahedrons in a sub-cube with corresponding state vectors.

Figure 9 shows the complete block diagram of the algorithm. This algorithm is well suited due to the good performance

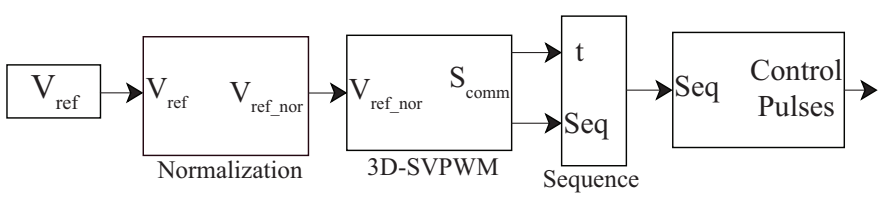

Fig. 9. Block diagram of 3D-SVPWM algorithm.

for multilevel converters and it can be used for converters with more levels applying a minimum of changes in its programming. The matrix with four commutation vectors and the corresponding switching times are defined by:

$$
S e c=\left(\begin{array}{cccc}
S_{a}^{1} & S_{a}^{2} & S_{a}^{3} & S_{a}^{4} \\
S_{b}^{1} & S_{b}^{2} & S_{b}^{3} & S_{b}^{4} \\
S_{c}^{1} & S_{c}^{2} & S_{c}^{3} & S_{c}^{4}
\end{array}\right)
$$




$$
t=\left(\begin{array}{c}
S_{1} \\
S_{2} \\
S_{3} \\
S_{4}
\end{array}\right)
$$

\section{Simulation Results}

The simulations results of the proposed APF are described in this section. A three-phase rectifier as nonlinear load has been connected to a $100 \mathrm{~V}, 60 \mathrm{~Hz}$ grid through filtering inductors. The APF operates at a switching frequency of $10 \mathrm{kHz}$ and regulates its internal DC voltage to $250 \mathrm{~V}$. Figure 10 shows the grid current effect in phase $a$ when the compensator is enable in $0.5 \mathrm{~s}$. Applying this selective harmonic compensator the total harmonic distortion (THD) has been reduced from $22.5 \%$ to $4.3 \%$.

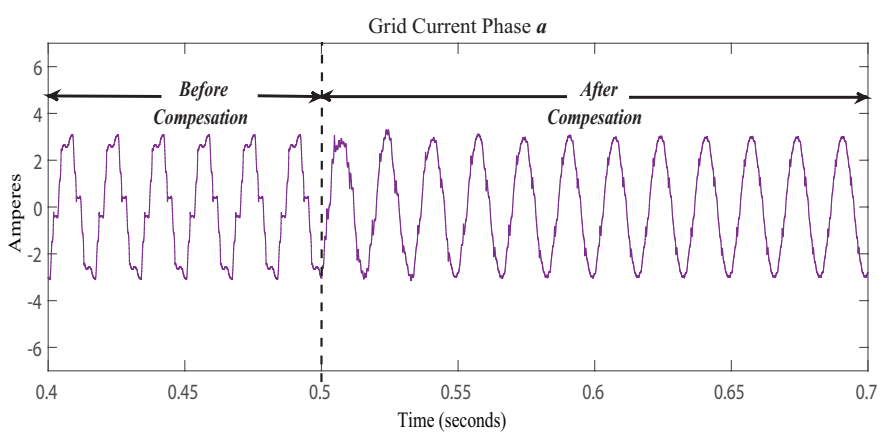

Fig. 10. Grid current in phase $a$ before and after compensation.

In Figure 11 is shown the three phase currents, before and after the compensation.

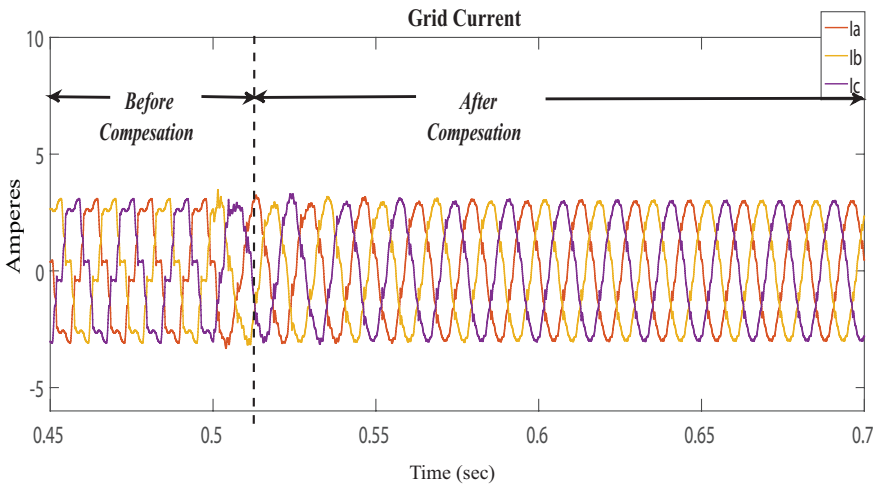

Fig. 11. Grid three phases currents before and after compensation.

In order to see the result of the individual harmonic control capability of the APF, Figure 12, show the effect of each harmonic compensated and the corresponding THD when this is activated.

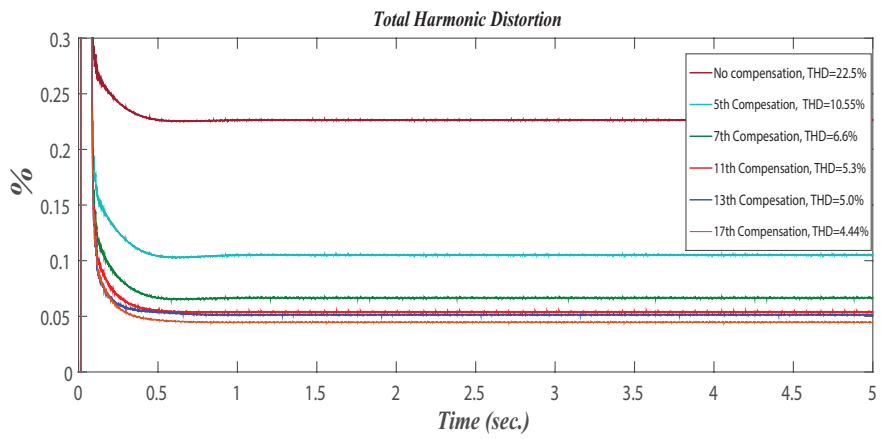

Fig. 12. Total harmonic distortion for each harmonic selected.

\section{CONCLUSION}

This paper presents the design and control of an active power filter based on 3-level NPC converter for selective harmonic compensation using synchronous reference frames. The controller for the selective harmonic compensation uses synchronous reference frames and a low pass filter in order to enables the control of individual harmonics using $d-q$ signals. Therefore, the derive control rules can be selected and applied, and the harmonic compensation is carried out without steady state error.

The use of three level converters and 3D-SVPWM provide an accurate generation of the harmonic currents with a lower harmonic content. Thanks to this, the active power filter based on the three level converter is an attractive application for power quality improvement application in distribution and sub transmission systems.

\section{REFERENCES}

[1] B. Singh, K. Al-Haddad, and A. Chandra, "A review of active filters for power quality improvement," IEEE Transactions on Industrial Electronics, vol. 46, no. 5, pp. 960-971, Oct 1999 .

[2] H. Akagi, Y. Kanazawa, and A. Nabae, "Instantaneous reactive power compensators comprising switching devices without energy storage components," IEEE Transactions on Industry Applications, vol. IA-20, no. 3, pp. 625-630, May 1984.

[3] S. Bhattacharya and D. Divan, "Synchronous frame based controller implementation for a hybrid series active filter system," in Industry Applications Conference, 1995. Thirtieth IAS Annual Meeting, IAS '95., Conference Record of the 1995 IEEE, vol. 3, Oct 1995, pp. 2531-2540 vol.3.

[4] J. C. Wu and H. L. Jou, "Simplified control method for the single-phase active power filter," IEE Proceedings - Electric Power Applications, vol. 143, no. 3, pp. 219-224, May 1996.

[5] D. Campos-Gaona, R. Peña-Alzola, J. L. Monroy Morales, and M. Ordonez, "Dynamic mitigation of grid current harmonics using the power sphere concept in voltage source inverters," in 2016 IEEE 7th International Symposium on Power Electronics for Distributed Generation Systems (PEDG), June 2016, pp. 1-8.

[6] H. H. Kuo, S. N. Yeh, and J. C. Hwang, "Novel analytical model for design and implementation of three-phase active power filter controller," IEE Proceedings - Electric Power Applications, vol. 148, no. 4, pp. 369383, Jul 2001.

[7] K. Zhou and D. Wang, "Relationship between space-vector modulation and three-phase carrier-based pwm: a comprehensive analysis [threephase inverters]," IEEE Transactions on Industrial Electronics, vol. 49, no. 1, pp. 186-196, Feb 2002. 
[8] D. P. Dorantes, J. L. Monroy Morales, and M. Hernández- Ángeles, "3dsvpwm vector control of a vsc-hvdc transmission system," in 2013 IEEE International Autumn Meeting on Power Electronics and Computing (ROPEC), Nov 2013, pp. 1-6.

[9] J. I. Leon, R. Portillo, L. G. Franquelo, M. M. Prats, and W. Kolomyjski, "New state vectors selection using space vector modulation in three dimensional control regions for multilevel converters," in 2006 IEEE International Symposium on Industrial Electronics, vol. 2, July 2006, pp. 1376-1381.

[10] J. I. Leon, S. Vazquez, R. Portillo, L. G. Franquelo, J. M. Carrasco, P. W. Wheeler, and A. J. Watson, "Three-dimensional feedforward space vector modulation applied to multilevel diode-clamped converters," IEEE Transactions on Industrial Electronics, vol. 56, no. 1, pp. 101-109, Jan 2009.

[11] J. L. Monroy Morales, M. Hernández-Ángeles, and F. H. V. Vargas, "A digital control for a three-dimensional sv-pwm multilevel converter," in 2014 IEEE International Autumn Meeting on Power, Electronics and Computing (ROPEC), Nov 2014, pp. 1-6.

[12] J.-H. Suh, C.-H. Choi, and D.-S. Hyun, "A new simplified space-vector pwm method for three-level inverters," in Applied Power Electronics Conference and Exposition, 1999. APEC '99. Fourteenth Annual, vol. 1, Mar 1999, pp. 515-520 vol.1.

[13] S. Bhattacharya, T. M. Frank, D. M. Divan, and B. Banerjee, "Active filter system implementation," IEEE Industry Applications Magazine, vol. 4, no. 5, pp. 47-63, Sep 1998

[14] J. L. Monroy-Morales, M. Hernández-Ángeles, D. Campos-Gaona, R. Peña-Alzola, M. Ordonez, and W. Mérida, "Modeling and control design of a vienna rectifier based electrolyzer," in 2016 IEEE 7th International Symposium on Power Electronics for Distributed Generation Systems (PEDG), June 2016, pp. 1-8. 